\title{
Retraction Note to: Adipose stromal-vascular fraction-derived paracrine factors regulate adipogenesis
}

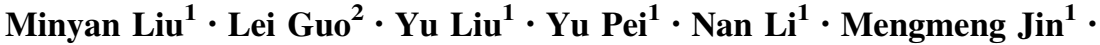 \\ Lichao $\mathrm{Ma}^{1} \cdot$ Zhibing $\mathrm{Li}^{1} \cdot$ Banruo Sun ${ }^{1} \cdot$ Chunlin $\mathrm{Li}^{1}$
}

Published online: 28 November 2015

(C) Springer Science+Business Media New York 2015

\section{Retraction Note to: Mol Cell Biochem (2014) 385:115-123 \\ DOI 10.1007/s11010-013-1820-6}

The Editor-in-Chief retracts this article as per the Committee on Publication Ethics (COPE) guidelines on plagiarism. After a thorough investigation this article was found to contain substantial sections that were taken from a
Ph.D. thesis (Molecular Mechanisms of Adipogenesis in Obesity and the Metabolic Syndrome) without proper attribution and acknowledgement.

The online version of the original article can be found under doi:10.1007/s11010-013-1820-6.

Chunlin Li

chunlinli301@126.com

1 Department of Elderly Endocrinology, Chinese PLA General Hospital, No. 28, Fuxing Road, Haidian District,

Beijing 100853, China

2 Department of Obstetrics and Gynecology, Beijing Tiantan Hospital, Capital Medical University, Beijing 100050, China 